\title{
Medicare Beneficiary ID
}

National Cancer Institute

\section{Source}

National Cancer Institute. Medicare Beneficiary ID. NCI Thesaurus. Code C120299.

An identification code, composed of the individual's social security number plus a suffix code, used by the Medicare system to uniquely identify a user and how that user qualifies for Medicare. 